This item was submitted to Loughborough's Research Repository by the author.

Items in Figshare are protected by copyright, with all rights reserved, unless otherwise indicated.

\title{
Positive and negative affect is related to experiencing chest pain during exercise-induced myocardial ischemia
}

PLEASE CITE THE PUBLISHED VERSION

https://doi.org/10.1097/PSY.0000000000000427

\section{PUBLISHER}

@ American Psychosomatic Society. Published by Lippincott, Williams \& Wilkins

\section{VERSION}

AM (Accepted Manuscript)

\section{PUBLISHER STATEMENT}

This work is made available according to the conditions of the Creative Commons Attribution-NonCommercialNoDerivatives 4.0 International (CC BY-NC-ND 4.0) licence. Full details of this licence are available at: https://creativecommons.org/licenses/by-nc-nd/4.0/

\section{LICENCE}

CC BY-NC-ND 4.0

\section{REPOSITORY RECORD}

Stebenne, Philippe, Simon L. Bacon, Anthony Austin, Nicola Paine, Andre Arsenault, Catherine Laurin, Bernard Meloche, Jennifer Gordon, Jocelyn Dupuis, and Kim L. Lavoie. 2019. "Positive and Negative Affect Is Related to Experiencing Chest Pain During Exercise-induced Myocardial Ischemia”. figshare. https://hdl.handle.net/2134/34444. 


\section{Positive and negative affect as related to experiencing chest pain during exercise- induced myocardial ischemia}

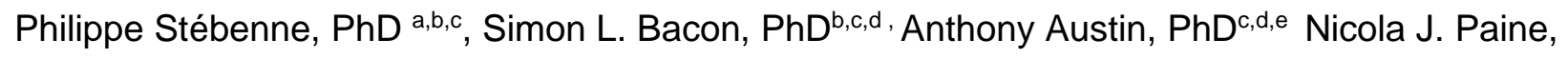
$\mathrm{PhD}^{\mathrm{c}, \mathrm{d}}$, André Arsenault, $\mathrm{MD}^{\mathrm{b}}$, Catherine Laurin, $\mathrm{PhD}^{\mathrm{c}}$, Bernard Meloche, $\mathrm{NMT}^{\mathrm{b}}$, Jennifer Gordon, PhD c,f, Jocelyn Dupuis, MD ${ }^{b}$, Kim L. Lavoie, PhD ${ }^{a, b, c^{*}}$

a Department of Psychology, University of Québec at Montréal (UQAM), 100 Sherbrooke St W, Montréal, Québec, H3C 3P8. Canada

${ }^{\mathrm{b}}$ Research Centre, Montreal Heart Institute, 5000 Bélanger East, Montréal, Québec, H1T 1 C8. Canada

${ }^{c}$ Montreal Behavioural Medicine Centre, Research Centre, Hôpital du Sacré-Coeur - CIUSS-

NIM, 5400 Gouin W., Montréal, Québec, H4J 1C5. Canada

'Department of Exercise Science, Concordia University, 7141 Sherbrooke St West, Montréal, Québec, H4B 1R6. Canada

e Department of Social and Behavioral Sciences, University of Arkansas at Pine Bluff, $1200 \mathrm{~N}$. University Drive, Pine Bluff, Arkansas, 71601, USA

f Department of Psychology, University of Regina, 3737 Wascana Parkway, Regina, Saskatoon, S4S 0A2. Canada

*Address for reprints (corresponding author): Kim L. Lavoie, PhD, Montreal Behavioural Medicine Centre, Research Centre J-3140, Hopital du Sacre-Coeur de Montreal, CIUSS-NIM, 5400 Gouin Blvd. West, Montreal, QC, Canada, H4J 1C5

Tel: (514) 338-2222 ext. 3709. Fax: (514) 338-3123. Email: k-lavoie@crhsc.rtss.qc.ca 
Funding support: Funding for data collection was provided by an operating grant from the Heart and Stroke Foundation of Quebec (HSFQ), and investigator awards from the Canadian Institutes of Health Research (CIHR) and the Fonds de recherche du Quebec: Sante (FRQS) (KLL \& SLB). Doctoral scholarship support was provided by the Social Sciences and Humanities Research Counsel of Canada (PS). Postdoctoral scholarships were provided by the Ministere de l'education et du loisir du Quebec (AA), FRQS (NJP) and CIHR (NJP).

Conflict of Interest: The authors declare no conflict of interest.

Word Count: 4839

Abstract count: 249

Number of Tables: 4

Number of Figures: 2

Abbreviated Title: Affect and chest pain during exercise 


\begin{abstract}
Objective: Silent myocardial ischemia is thought to be associated with worse cardiovascular outcomes due to a lack of perception of pain cues that initiate treatment seeking. Negative affect (NA) has been associated with increased pain reporting and positive affect (PA) with decreased pain reporting, but these psychological factors have not be examined within the context of myocardial ischemia. This study evaluated the associations between PA, NA and chest pain reporting in patients with and without ischemia during exercise testing.

Methods: 246 patients referred for myocardial perfusion single photon emission computed tomography exercise stress testing completed the PANAS-X, a measure of PA and NA. Presence of chest pain and myocardial ischemia were evaluated using standardized protocols.

Results: Logistic regression analyses revealed that for every 1 point increase in NA, there was a $13 \%$ higher chance for ischemic patients $(\mathrm{OR}=1.13 ; 95 \% \mathrm{Cl}=1.02-1.26)$ and an $11 \%$ higher chance in non-ischemic patients $(\mathrm{OR}=1.11 ; 95 \% \mathrm{Cl}=1.03-1.19)$ to report chest pain. A significant interaction of $\mathrm{PA}$ and $\mathrm{NA}$ on chest pain reporting $(\beta=0.02 ; 95 \% \mathrm{Cl}=0.002-0.031)$ was also observed; non-ischemic patients with high NA and PA reported more chest pain (57\%) versus patients with low NA and PA (13\%), with high NA and low PA (17\%), and with high PA and low NA $(7 \%)$.

Conclusions: Patients who experience higher NA are more likely to report experiencing chest pain. Patients without ischemia are also more likely to report chest pain. Results suggest that reporting high levels of positive and negative affect may influence the experience and/or reporting of chest pain.
\end{abstract}

Keywords: positive affect, negative affect, silent ischemia, chest pain, coronary heart disease 
Abbreviations: $\mathbf{A H A}=$ American Heart Association; $\mathbf{C A D}=$ coronary artery disease $; \mathbf{C l}=$ Confidence interval; CVD = cardiovascular disease; ECG = Electrocardiographic; $\mathbf{G L M}=$ Generalized linear model; HR = Hazard ratio; $\mathbf{I H D}=$ ischemic heart disease; $\mathbf{M H I}=$ Montreal Heart Institute; $\mathbf{M H C L}=$ Multicomponent Health Locus of Control MOSMI = Cross-sectional Mechanisms and Longitudinal Outcomes of Silent Myocardial Ischemia study; NA = negative affect; $\mathbf{O R}=$ Odd ratio PA = positive affect; $\mathbf{P A N A S - X}=$ Positive and Negative Affect Scheduleexpanded version; SPECT = single photon emission computed tomography 


\section{Introduction}

According to the World Health Organization, cardiovascular disease (CVD) is the number one cause of mortality worldwide (1). Of all forms of CVD, coronary artery disease (CAD) is responsible for the majority of morbidity and mortality (2). The American Heart Association (AHA) reported that 15.5 million persons in the United States have CHD, including 8.2 million with angina pectoris (2). Myocardial ischemia is a condition triggered by an imbalance between myocardial oxygen supply and demand $(3,4)$, and is a key predictor of future CVD events and outcomes (57).

Importantly, myocardial ischemia may or may not be accompanied by chest pain $(3,4)$. However, most ischemic episodes (i.e., 70\%-75\%) occur in the absence of chest pain, a condition known as "silent ischemia" (4, 8-10). The occurrence and detection of chest pain during an ischemic episode may be critical for self-initiation of treatment (e.g., taking vasodilators) or timely presentation to the emergency department (ED), both of which may reduce cardiac morbidity and mortality (11). Delays in treatments or presentation for assessment are likely reasons why patients with silent ischemia are at increased risk for cardiac events and mortality $(8,10)$. Accurate chest pain perception during episodes of ischemia may be even more critical for patients with previously undiagnosed CAD, due to lack of awareness of a pre-existing cardiac condition. The AHA estimates that approximately two-thirds of women and half of men who died suddenly of CAD had no prior CAD history (2). Therefore, determining factors associated with accurate chest pain perception in the context of ischemia represents an important clinical research goal. In addition to the links between CVD outcomes and ischemia, there is also a documented link between psychiatric disorders and CVD development and outcomes (12, 13). Negative affect (e.g., depressed mood and anxiety) is a strong predictor of future CVD events and outcomes $(12,13)$, and has been linked to clinical markers of CVD such as exercise induced ischemia $(14,15)$, as well as, poor pain perception $(16,17)$. 
Pain perception is a multidimensional experience involving physical pain sensitivity and accurate interpretation of pain sensations (18). Accurate pain perception may be influenced by negative and positive affect. Collectively, the general affect-pain literature suggests that negative affect (NA: e.g., anxiety, anger) may increase and positive affect (PA: e.g., happiness, joy) may decrease pain perception or sensitivity (19). For example, patients exposed to high situational anxiety tend to report higher levels of pain intensity in response to the cold pressor test (20), with trait anger positively correlated with pain perception (21). Also, patients with higher levels of anger and frustration are more likely to experience cancer-related pain at greater intensity levels and for longer durations compared to patients with lower levels of anger and frustration (22). Previous studies have demonstrated that measures of NA, such as depression, are generally associated with greater pain symptom reporting in patients with and without CVD $(16,17)$, as well as higher reported pain intensity in post-surgical patients (23). However, higher general NA has also been shown to predict the presence of exercise-induced angina (24). Anxiety, another measure of NA, has been linked to higher reports of chest pain among cardiac and non-cardiac populations ( 25 , 26). In contrast, patients with silent ischemia (no chest pain) appear to have lower levels of depression and anxiety (27).

Little is known as to whether negative affect can influence the reporting and presence of chest pain when myocardial ischemia is also present, nor whether negative affect can lead to increases in chest pain reporting when there is no other physiological symptom of disease such as myocardial ischemia. Untangling whether negative affect can lead to the reporting of chest pain which may be 'phantom pain', or psychosomatic in nature, is clinically important, as accurate pain perception may be critical for timely and potentially life-saving intervention $(20,28-31)$.

Studies in chronic disease populations (e.g., rheumatoid arthritis, fibromyalgia and sicklecell disease), have shown that higher levels of PA are associated with reduced pain perception (29-31), lower pain intensity $(29,30)$, and reduced perceptions of pain intensity $(19,31)$. In the 
context of CVD, increased PA has been linked with a reduced risk of stroke, decreased hospital readmission after a cardiac events and lower mortality in cardiac patients (32-34). However, there is minimal information on the role of positive affect (PA) on chest pain perception in the context of CVD.

In the majority of the CVD literature, studies have focused on either NA or PA and few have assessed both in the same study. This limitation is notable given that the dynamic model of affect suggests that in a chronic, stressful situation (e.g., chronic pain), a high level of NA could suppress the capacity of PA to compensate by becoming the only information that is processed by the brain (35). This model also suggests that under normal circumstances, PA and NA are processed by distinct neural process and they can be manipulated independently (35). Thus examining the role of NA and PA concurrently is important, particularly in the context of detecting chest pain and ischemia, to examine if NA or PA play a buffering role on chest pain reporting and whether this could mask clinically important factors such as ischemia and chest pain.

Thus, the objective of the present study was to assess associations between PA and NA and chest pain perception among patients who presented for diagnostic exercise stress testing. We hypothesized that patients with higher levels of NA would be more likely to report experiencing chest pain during exercise compared to patients with lower levels of NA, and that patients with higher levels of PA would be less likely to report chest pain during exercise compared to patients with lower levels of PA, particularly among patients in whom ischemia is not induced during exercise testing.

\section{Methods}

\section{Participants}

This study was a sub-study of the Cross-sectional Mechanisms and Longitudinal Outcomes of Silent Myocardial Ischemia (MOSMI) Study, a prospective study designed to 
examine the impact of blood pressure and pain on myocardial ischemia. Participants presenting to the Montreal Heart Institute (MHI) for single photon emission computed tomography (SPECT) exercise stress testing were recruited between May 2005 and December 2006. Exclusion criteria were: 1) already participating in another study at the MHI; 2) pregnant or nursing; 3) taking nonsteroid anti-inflammatory drugs in the 7 days prior to stress-test; 4) taking an analgesic the day of the stress test; 5) suffering from a major medical condition other than CAD (e.g., cancer, AIDS); 6) suffering from any severe mental disorder (e.g., schizophrenia) or evidence of current substance abuse; 7) less than 18 years old; 8) unable to speak/understand English or French or 9) suffering from a pain disorder other than angina. Our definition of a pain disorder was based on the DSM-IV definition of pain disorder which included chronic pain in one or more areas thought to have psychogenic origin and related neurologic conditions (phantom pain, hyperalgesia, hypoalgesia), but did not include musculoskeletal pain or back/pelvic pain.

A total of 2138 participants presented to the Nuclear Medicine Department of the MHI for an exercise stress test prescribed by their doctor during the recruitment period, of which 1174 patients $(55 \%)$ were approached to participate. Due to a lack of personnel, some patients were not approached if they presented simultaneously for their stress test. As shown in Figure 1, 124 patients were excluded, resulting in 1050 eligible participants. Only 143 participants declined to participate, yielding a final sample of 907 participants ( $86 \%$ participation rate). Late introduction of this sub-study in the larger MOSMI study (after the $582^{\text {th }}$ patient), missing data, and participant attrition, left a final participating sample of 246 participants for this sub-study. There were no significant differences between this subgroup and the remaining MOSMI sample (i.e., the 661 individuals not included in this sub-study) in demographic or clinical data, i.e., age, sex, presence of clinical pain, ischemia, silent ischemia or previous cardiac diseases. The MHI scientific and ethics committees approved this study, and all patients provided written, informed consent. 


\section{Procedure}

Patients were informed of the study procedures and a trained clinical research assistant obtained informed consent. Eligible and consenting patients underwent a standard treadmill exercise stress test (modified Bruce protocol). The stress test was followed by SPECT imaging under the supervision of a nuclear medicine physician according to standard procedure $(36,37)$. Patients were maintained on their usual medication throughout the protocol. Participants were then asked to complete a socio-demographic and medical history questionnaire, followed by the self-report Positive and Negative Affect Schedule-expanded version (PANAS-X) (38).

\section{Measures}

Positive and Negative Affect Schedule- Expanded. PA and NA were evaluated using the PANAS-X, which measures state and trait constructs of positive and negative affect experienced in the last few weeks (38). The PANAS has 60 items, rated on a scale from 1 to 5 ( $1=$ very slightly or not at all; $5=$ extremely) to yield overall PA and NA scores as well as scores on subscales of negative (Fear, Sadness, Guilt, Hostility, Shyness, Fatigue) and positive (Surprise, Joviality, Self-Assurance, Attentiveness, and Serenity) affect. NA was calculated by summing the scores for the following constructs: afraid, scared, nervous, jittery, guilty, ashamed, irritable, hostile, upset and distressed. PA was calculated as the sum of: active, alert, attentive, enthusiastic, excited, inspired, interested, proud, strong and determined. This is in line with the PANAS-X scoring manual (38). Conceptually, the PA and NA scales are independent dimensions, such that patients can score anywhere along the continuum of each scale (i.e., patients can score high on both PA and NA) $(38,39)$. The mean of each scale is calculated for each patient to determine overall positive and negative affect levels. Internal reliability ranges from .85 to .90 for the NA scale and from .83 to .90 for the PA scale (38). The PANAS-X 
subscales have demonstrated excellent psychometric properties, including excellent convergent validity ( $r=.85$ to .91$)$ with the Profile of Mood States and good and moderate correlations, respectively, for the PA and NA subscales of the Global Mood Scale (PA $=0.79$ and NA $=0.56)$ $(38,40,41)$. Both PA and NA scales have good stability over 2 months (test-retest correlations of 0.71 and 0.70 , respectively) (38). A standard forward-backward translation of the PANAS-X was performed to translate the PANAS-X into French. The internal reliability ranges were from .81 to .86 for the individual constructs of the NA scale and from .81 to .89 for the individual constructs of the PA scale for the whole sample; specifically the internal reliability coefficients were .87 for PA and .81 for NA both English version) and .87 for PA and .86 for NA for the translated French version of the PANAS-X.

Chest pain assessment. Chest pain perception during treadmill exercise stress testing was evaluated by a trained exercise stress test technician and overseen by a cardiologist, who asked patients to self-report the presence and intensity of any chest pain occurring during the test using a 10-point rating scale (42). Patients with a score of greater than 0 were considered to be experiencing chest pain. Ultimately, the cardiologist determined whether the pain was related to an underlying cardiac or non-cardiac condition (e.g., back pain) according to standard procedure (43). Patients who had confirmed exercise-induced chest pain were classified as having anginarelated chest pain; those without were classified as having no chest pain.

Ischemia assessment. SPECT assessments of reversible myocardial perfusion defects at peak exercise were evaluated by experienced nuclear medicine physicians according to the standard procedure $(36,37)$ using an Irix-3 model camera (Philips, Cleveland, Ohio). The objective of the visual assessment of SPECT myocardial perfusion images was to determine if there were defects on stress images and whether these defects were reversible on the rest SPECT images (44). A total of 21 segments were analysed for each patient, with at least 2 reversible defects were needed in order to classify the patient as having ischemia. Patients were 
determined to have had silent ischemia if they had evidence of ischemia on the SPECT scan but reported no chest pain, discomfort or other angina equivalent during their treadmill test (44).

\section{Statistical analyses}

Primary analyses. Baseline variables are presented as means \pm SD and proportions $(n)$ for continuous and categorical variables, respectively. General Linear Models were used to determine baseline variable differences as a function of group. These groups were: 1) No Chest Pain; No Ischemia; 2) Silent Ischemia; 3) Chest Pain; No Ischemia; 4) Ischemia with Chest Pain. Correlations (or chi-square analyses, where appropriate) were used to determine relationships between NA, PA, Ischemia and Chest Pain. A series of logistic regressions analyses adjusting for age, sex, total exercise METS, prescription of anti-ischemic medications, and analgesic medication use (not initially reported during recruitment) on the day of the test were used to assess main and interaction effects of PA and NA on chest pain perception. Identical analyses also investigated the 3-way interaction between PA, NA and ischemia, with further examination of the interaction between PA and NA completed for patients with and without ischemia, separately. For the analyses PA and NA were used continuously. Estimates from the multiple imputation analysis for the main and interaction effects are reported in tables. Corresponding odds-ratios for the main effects are reported in the text. As per previous examples (45), upper and lower quartiles of NA and PA were used to graphically represent the nature of any statistically significant interactions. All covariates were determined a-priori based on previously established associations with the dependent variables (14).

Imputation of missing data. Using Rubin's rules (46) our missing data analysis procedures used multiple imputation (47) with missing at random (MAR) assumptions. There were no systematic differences in the amount of missing data across groups. Using the PROC MI method of multiple multivariate imputation in SAS, we independently analyzed 20 copies of the 
data. PROC MIANALYZE was used according to Harrell's guidelines (48). Details of the amount of missing data per variables are included in Table 1. All analyses were 2-tailed and significance was set at $p<.05$. All statistical analyses were conducted using SAS V. 9.3 (SAS Institute, Cary, $\mathrm{NC})$.

\section{Results}

\section{Participant characteristics}

Patients were $65 \%$ male with a mean age of $59.9(\mathrm{SD}=10.57)$ years (range 27 to 83 years old). $95 \%$ were White, $73 \%$ were cohabitating with a partner, and the mean number of years of education was $13.7(S D=4.1)$ years. The participants' mean body mass index $(\mathrm{BMI})$ was 27.8 $(\mathrm{SD}=4.5) \mathrm{kg} / \mathrm{m}^{2}$ (overweight range) and $13 \%$ were current smokers. A total of $24 \%$ of the sample had a previous myocardial infarction, $61 \%$ were hypertensive, and $14 \%$ had diabetes. Comparisons of socio-demographics and clinical characteristics as a function of chest pain and ischemia status are presented in Tables 1 and 2. The analyses showed significant differences between the two ischemia groups (with and without chest pain) and the no ischemia groups (with and without chest pain) on BMI, hypertension, cholesterol, any coronary heart disease, previous myocardial infarction, and diabetes, with higher prevalence seen in the ischemia groups. Similarly, the analyses also showed that the ischemia groups were prescribed more medication than the no ischemia groups.

Among the 246 patients, 78 (31.7\%) patients developed exercise-induced ischemia. Exercise-induced ischemia with chest pain was observed in $23(9.35 \%)$ patients, 55 (22.4\%) had ischemia without chest pain (silent ischemia), 23 (9.35\%) no ischemia but nonetheless reported chest pain. Patients with inducible ischemia had more often chest pain during exercise $(29.5 \%$ vs $13.7 \%, \mathrm{X} 2=8.74, p=.003))$ and a higher pain severity score $(1.19 \pm 2.43$ vs. $0.72 \pm 1.92)$ compared to patients without ischemia. Eight / 85 women (9.1\%) developed ischemia, compared 
to $71 / 163(43.6 \%)$ men $(p<.001)$, whereas no sex differences were found in reported chest pain $(20.0 \%(\mathrm{M})$ vs $17.7 \%(\mathrm{~W}), p=.65)$.

\section{PA, NA, and the relationships to chest pain and ischemia.}

The mean PA and NA scores were $29.3 \pm 6.9$ and $17.2 \pm 6.2$ respectively. There was a negative correlation between NA and PA $(r=-.34, p<.001)$, indicating that patients with higher negative affect reported lower levels of positive affect. Furthermore, chest pain was correlated with NA $(r=.23, p<.001)$ but not PA $(r=.04, p=.55)$. Ischemia was not associated with NA ( $r$ $=-.01, p=.88)$ nor PA $(r=-.04, p=.51)$. Analysis of differences in NA and PA by group (no ischemia, no chest pain; silent ischemia; chest pain, no ischemia; chest pain and ischemia) revealed an effect of group for NA $(F=4.44, p=.004)$. Post hoc analysis revealed the highest levels of NA in the group with chest pain and ischemia, and the lowest NA in the no chest pain no ischemia group. These differences are displayed in Table 1.

Regarding exercise stress test characteristics (Table 2), there were no significant main effects of group for test duration, Metabolic equivalents (METs), baseline SBP, baseline DBP or baseline HR (all p's > .05). While there were no main effects of group for peak SBP or peak DBP, there was a main effect of peak HR $(F=2.75, p=.044)$. Post-hoc analyses revealed patients who experienced ischemia with chest pain or silent ischemia had significantly lower peak HR's compared to patients with no chest pain and no ischemia (both $p$ 's $<.05$ ). There were no post-hoc differences in peak HR between patients with chest pain but no ischemia and patients with no chest pain and no ischemia. There was also a main effect of group for patients who achieved their Maximum Predicted Heart Rate (MPHR) $(F=4.65, p=.004)$. Post-hoc analyses revealed that patients with ischemia and chest pain had a lower number of patients who did not reach their MPHR compared to patients with no ischemia and no chest pain, and 
compared to patients who had silent ischemia $(p$ 's $<.05)$. There were no other group differences. Unsurprisingly, there also group differences for self-reported chest pain $(F=$ 119.27, $p<.001)$, where patients with chest pain and no ischemia, and patients with ischemia and chest pain had higher self-reported chest pain than the patients with silent ischemia and patients with no chest pain and no ischemia (all p's <.05).

\section{Associations between PA, NA and ischemia on chest pain}

A series of Logistic regressions examined the associations between PA, NA and ischemia on chest pain (see Table 3). Across the whole sample, we saw associations between $\mathrm{PA}(\mathrm{OR}=1.01,95 \% \mathrm{Cls}=1.00-1.02, p=.038)), \mathrm{NA}(\mathrm{OR}=1.02,95 \% \mathrm{Cls}=1.01-1.02, p<$ $.001)$ and ischemia $(\mathrm{OR}=1.17,95 \% \mathrm{Cls}=1.04-1.31, p=.007)$ on chest pain, which were significant having adjusted for age, sex, total exercise METS, prescription of anti-ischemic medications, and analgesic medication use. Furthermore, across the whole sample, we also saw trends for an interaction between PA and NA $(\beta=-0.001,95 \% \mathrm{Cls}=-0.00-0.00, p=.07)$, after adjusting for covariates, including ischemia. In addition, there was a trend for an interaction between $\mathrm{PA}$ and ischemia $(\beta=0.04,95 \% \mathrm{Cls}=-0.005-0.08, p=.079)$, a significant interaction between NA and ischemia $(\beta=0.07,95 \% \mathrm{Cls}=0.01-0.13, p=0.02)$ and a trend for a 3-way interaction between PA, NA and ischemia $(\beta=-0.002,95 \% \mathrm{Cls}=-0.004-0.00, p=0.069)$ in the association with pain.

Interrogation of the 3-way interaction was undertaken, stratifying patients by ischemia status. As detailed in Table 4, the analysis revealed that in patients with ischemia, there was a significant effect of $\mathrm{NA}(\mathrm{OR}=1.13 ; 95 \% \mathrm{Cls}=1.02-1.26)$ but not for $\mathrm{PA}(\mathrm{OR}=1.06 ; 95 \% \mathrm{Cls}=$ 0.96-1.12) for the association between reporting chest pain, indicating that patients with higher levels of NA were more likely to report experiencing chest pain during exercise. In the interaction model, there was no interaction effect of PA and NA. In patients without ischemia, 
higher levels of NA were also associated with an increased frequency of reporting chest pain during the stress test. As detailed in Table 4, the main effects analysis in patients without ischemia mirrored that of the ischemia patients with a statistically significant association between for $\mathrm{NA}(\mathrm{OR}=1.11 ; 95 \% \mathrm{Cls}=1.03-1.19)$ but not $\mathrm{PA}(\mathrm{OR}=1.07 ; 95 \% \mathrm{Cls}=0.99-1.15)$. Among patients without ischemia, there was also a significant interaction between PA and NA on chest pain reporting, where patients with higher levels of both NA and PA were more likely to report chest pain $(\beta=0.02 ; 95 \%$ Cls $=0.002-0.03)$ compared to patients with low levels of NA and PA (see Figure 2).

\section{Discussion}

The objective of the present study was to examine relationships between PA/NA and chest pain perception in the context of ischemia in patients undergoing exercise stress tests. We expected that patients with higher levels of NA would be more likely to report chest pain, and patients with higher levels of PA would be less likely to report chest pain, particularly among those with ischemia (silent ischemia). Our hypotheses were only partially supported: with higher levels of NA being associated with an increased frequency of reporting chest pain in both ischemia and non-ischemia patients. However, higher levels of PA alone were not associated with a reduction in chest pain reporting; higher NA was associated with an increased chance of chest pain reporting, irrespective of ischemic status. Interestingly, we observed an interaction between PA and NA on chest pain reporting in the non-ischemic patients only, such that patients with higher levels of both PA and NA had a greater probability of reporting chest pain. This suggests that patients with overall higher levels of both NA and PA are more likely to report experiencing chest pain during exercise stress tests, especially in the absence of ischemia. However, ischemia was

not associated with NA nor PA. Our study uniquely presents evidence of the interactive and 
dynamic associations of both NA and PA in the context of ischemia and chest pain reporting, particularly the unique association of elevated affect in those who do not have ischemia.

In terms of the magnitude of our associations, our findings suggest that every 1 point increase in NA was associated with a $13 \%$ and $11 \%$ greater chance of reporting chest pain during exercise in patients with and without ischemia, respectively. These results are generally consistent with previous reports (24). Previous studies have demonstrated that NA affect measures, such as depression, are associated with greater symptom reporting in patients with and without CVD $(16,17)$. Another study demonstrated that higher levels of anxiety and depression, evaluated by the Hospital Anxiety and Depression Scale (HADS), were associated with higher reported pain intensity in post-surgical patients (23). Anxiety, another measure of NA, has also been linked to higher reports of chest pain among cardiac and non-cardiac populations $(25,26)$. It is though that these relationships may be due to changes in a combination of physiological systems such as the autonomic nervous system, coronary vasculature system including increased microvascular resistance (26) , as well as possibly due to fears associated with having cardiac events $(49,50)$. Patients with a high level of anxiety have a greater tendency to catastrophize somatic symptoms, which has been related to increase pain reporting (51). Patients with anxiety may also be hyper-vigilant to chest pain and report more chest pain during a stress test (52). Our findings are also consistent with a study reporting that most patients seeking emergency care for non-cardiac chest pain report higher levels of NA (e.g., depression and history of panic) (49). Similarly, patients with a high level of neuroticism (a personality trait where individuals are more likely to experience anger, anxiety, and depression) report more chest pain or discomfort than patients with a lower level of neuroticism $(17,53)$. Though the mechanisms linking negative affective states and pain perception have not been fully delineated, one possibility is impairments of the endogenous opioid system in the anterior cingulated cortex, 
which is involved in pain regulation (54). When impaired, this system is associated with a reduced ability to modulate negative emotions as well as elevated pain sensitivity (54).

Contrary to our hypotheses, we did not observe any associations between higher levels of PA alone and reduced pain reporting, irrespective of ischemia. Rather, we observed that PA was related to increased chest pain reporting, and demonstrated a significant interaction between PA and NA and reports of chest pain in non-ischemic patients. In this group, patients with higher levels of both PA and NA reported more chest pain compared to other patients. This is particularly interesting, given that patients with high NA and low PA did not report the same prevalence of the presence of chest pain compared to high NA/high PA patients. A previous study demonstrated that patients with higher levels of "emotionality" reported more incongruent lower back pain (inappropriate symptomatic complaints or nonorganic physical signs) (55), which parallels our findings. Though we did not directly assess "emotionality", it is possible that scoring high on both PA and NA may reflect the same construct. In contrast to our findings, it has been observed that anhedonic patients have a tendency to report more somatic symptoms (56). An alternative hypothesis is that patients with high levels of PA, including feelings of assertiveness and selfassurance, could also be displaying proactive health behaviors by reporting that they are experiencing chest pain. Others have shown that positive affect is related to internal components of the Multicomponent Health Locus of Control (MHLC) (57). However, as we did not assess MHLC in our sample this must remain speculative. To our knowledge, this is the first study to specifically assess the association between PA and pain reporting in the context of ischemia. Though our findings did not support an association, they do add to the extant literature on the psychological factors that may (or may not) be involved in chest pain in cardiac patients.

Results of the present study should be interpreted in light of some limitations. First, patient selection was not random and participants were predominantly male and White, so results may not generalize to women or a non-White population. Second, though the sex ratio in our study is 
consistent with that seen in a clinical setting, due to the uneven proportions of men and women and low absolute numbers of women, we were not able to examine sex differences in chest pain reporting and ischemia as a function of PA and NA. Many studies report that women are more likely to exhibit lower pain thresholds, have a lower tolerance to noxious stimuli, and report more somatic complaints compared to men (58). Women also describe their chest pain differently than men and report greater pain intensity relative to men (59). Although we adjusted for sex in our analyses, future studies should aim to examine sex differences in these associations. Also, the pain measure used in this study was dichotomous (presence or absence of chest pain). This does not allow us to assess potential differences in pain quality as a function of PA or NA. Furthermore, it should be noted that this is a population who were undergoing exercise stress testing and, as such, individuals with conditions that interfered with their ability to exercise (e.g., severe musculoskeletal pain) would have been ineligible for such a test, and our findings should be viewed in light of this. One important consideration is the broader role of psychological characteristics which may influence chest pain and reporting of chest pain $(50,60)$. Furthermore, patients with CAD are more likely to under-report their emotional distress compare with patients with less severe cardiac condition (61). This may have disproportionally influenced the chest pain reported in the ischemia group. Furthermore, patients with CHD (or more severe CHD) may be more likely to under-report emotional distress relative to patients with less severe CHD symptomology. This disparity could have influenced the NA-PA reporting in the ischemia group, and should be considered in light of our findings.

Despite some limitations, this study also has several important strengths. To our knowledge, this study is the first to investigate the relationship between PA and NA and their interaction on chest pain reporting among patients with and without ischemia, adding critical new information. Second, compared to pain perception studies in general, our sample size is relatively large at 246. Though we had uneven proportions of men and women in the study, the percentage 
of men $(65 \%)$ in our sample reflects the disproportionately male cardiac population referred for an exercise SPECT tests, and is thus highly representative of this population. Third, experienced cardiologists conducted the chest pain and ischemia assessments according to standard procedures. Fourth, PA and NA was assessed using the PANAS-X, which is an excellent assessment of affect with very good psychometric properties.

Our results indicate that irrespective of ischemia, patients who experience greater levels of NA or PA are more likely report experiencing chest pain. However, among patients without ischemia, those reporting generally high levels of both NA and PA are also more likely to report chest pain. Given that patients with high NA have higher odds to report chest pain, whether or not they have ischemia, practitioners should be vigilant if patients exhibit or report symptoms' of negative mood, as this may influence the perception and experience of chest pain among patients undergoing diagnostic exercise stress testing, which may impact clinical findings. They should also consider that the pain reported in those patients may or may not be related to underlying ischemia. (28). Given that both high PA and NA appear to be important, more studies are needed to further disentangle the relationship between positive and negative emotions and pain perception in the context of ischemic heart disease. 
Table 1: Participant sociodemographic characteristics

\begin{tabular}{|c|c|c|c|c|c|c|c|}
\hline $\mathbf{N}(\%)$ or $\mathbf{M} \pm \mathrm{SD}$ & $\begin{array}{l}\text { No Chest Pain; } \\
\text { No Ischemia } \\
(n=145)\end{array}$ & $\begin{array}{l}\text { Silent Ischemia } \\
\qquad(n=55)\end{array}$ & $\begin{array}{l}\text { Chest Pain; No } \\
\text { Ischemia } \\
(n=23)\end{array}$ & $\begin{array}{l}\text { Ischemia with } \\
\text { Chest Pain } \\
(n=23)\end{array}$ & $\begin{array}{l}\mathbf{N} \text { missing } \\
\text { data }\end{array}$ & $F / x^{2}$ & $\mathbf{p}$ \\
\hline \multicolumn{8}{|l|}{ Sociodemographics } \\
\hline Age & $58.3 \pm 11$ & $63.7 \pm 9.7^{a}$ & $59.7 \pm 11.3$ & $58.7 \pm 7$ & 0 & 3.57 & .015 \\
\hline Sex (\% female) & $66(46)$ & $4(7)^{a}$ & $11(48)^{b}$ & $4(17)^{a, c}$ & 0 & 11.46 & $<.001$ \\
\hline White & $140(97)$ & $51(94)$ & $21(91)$ & $23(100)$ & 1 & .89 & .45 \\
\hline Living with a partner & $115(69)$ & $42(78)$ & $17(74)$ & $19(83)$ & 1 & .95 & .42 \\
\hline Years of education & $14.1 \pm 4.4$ & $13.83 \pm 3.7$ & $13.3 \pm 3.6$ & $11.4 \pm 3.7^{a, b}$ & 16 & 2.81 & .040 \\
\hline \multicolumn{8}{|c|}{ Medical history characteristics } \\
\hline $\mathrm{BMI}$ & $27.5 \pm 4.7$ & $29.3 \pm 3.9$ & $27.6 \pm 4.6$ & $29.3 \pm 3.8$ & 3 & 1.32 & .27 \\
\hline Hypertension & $77(53)$ & $39(72)^{a}$ & $15(65)$ & $19(83)^{a}$ & 1 & 3.91 & .009 \\
\hline Hyperlipidemia & $78(54)$ & $42(78)^{a}$ & $16(69)$ & $20(87)^{a}$ & 1 & 5.51 & .001 \\
\hline Current smoker & $18(9)$ & $8(4)$ & $2(4)$ & $3(7)$ & 6 & 3.79 & .15 \\
\hline Former smoker & $70(36)$ & $32(16)$ & $11(24)$ & $14(30)$ & 6 & 1.56 & .46 \\
\hline Diabetes & $15(10)$ & $7(16)^{a}$ & $0^{b}$ & $5(22)^{c}$ & 1 & 4.49 & .004 \\
\hline
\end{tabular}




\begin{tabular}{|c|c|c|c|c|c|c|c|}
\hline \multicolumn{8}{|l|}{ Cardiac history } \\
\hline Any CHD & $41(28)$ & $30(55)^{a}$ & $6(26)^{b}$ & $15(65)^{a, c}$ & 9 & 7.5 & $<.001$ \\
\hline Previous MI & $22(16)$ & $19(40)^{a}$ & $4(20)$ & $10(48)^{a, c}$ & 21 & 6.14 & $<.001$ \\
\hline Previous CABG & $12(9)$ & $5(11)$ & $1(5)$ & $6(32)^{a, b, c}$ & 29 & 3.25 & .023 \\
\hline Previous $\mathrm{PCl}$ & $22(16)$ & $16(36)^{a}$ & $4(19)$ & $10(53)^{a, c}$ & 25 & 6.20 & $<.001$ \\
\hline \multicolumn{8}{|l|}{ Medications } \\
\hline ACE-inhibitors & $19(13)$ & $13(24)^{a}$ & $4(17)$ & $9(39)^{a, c}$ & 2 & 3.87 & .010 \\
\hline Beta-blockers & $40(28)$ & $17(31)$ & $7(30)$ & $13(57)^{a, b, c}$ & 2 & 2.57 & .055 \\
\hline $\begin{array}{l}\text { Any Anti Blood } \\
\text { Pressure }\end{array}$ & $61(42)$ & $37(69)^{a}$ & $10(43)$ & $18(78)^{a, c}$ & 2 & 6.76 & $<.001$ \\
\hline ARB & $16(11)$ & $13(24)^{a}$ & $1(4)^{b}$ & $4(17)$ & 2 & 2.56 & .055 \\
\hline Diuretics & $16(11)$ & $8(15)$ & $9(4)$ & $4(17)$ & 2 & .81 & .49 \\
\hline Ca-Channel blockers & $19(13)$ & $12(22)$ & $3(13)$ & $9(39)^{a, c}$ & 2 & 3.86 & .010 \\
\hline Vasodilators & $4(3)$ & $2(4)$ & $2(9)$ & $3(13)^{a}$ & 2 & 1.99 & .12 \\
\hline Any anti-ischemic & $52(36)$ & $27(50)$ & 9 (39) & $17(74)^{a, b, c}$ & 2 & 4.49 & .004 \\
\hline Lipid-lowering & $55(38)$ & $37(69)^{a}$ & $10(43)^{b}$ & $16(70)^{a}$ & 2 & 6.80 & $<.001$ \\
\hline
\end{tabular}




\begin{tabular}{|c|c|c|c|c|c|c|c|}
\hline \multicolumn{8}{|l|}{ Affect Scale Scores } \\
\hline Negative Affect (NA) & $16.8 \pm 5.9$ & $15.6 \pm 4.7$ & $19.8 \pm 6.7^{a, b}$ & $20.0 \pm 8.7^{a, b}$ & 2 & 4.44 & .004 \\
\hline Positive Affect (PA) & $29.1 \pm 7.0$ & $28.8 \pm 6.4$ & $30.6 \pm 7.1$ & $28.6 \pm 7.8$ & 1 & 0.41 & .74 \\
\hline
\end{tabular}

Note: $B M I$, body mass Index; $C H D$, Coronary heart disease; $M I$, myocardial infarction; $C A B G$, coronary artery bypass graft surgery;

PCl, Percutaneous coronary intervention; $A C E$, angiotensin converting enzyme; $A R B$, Angiotensin II receptor blockers $C a-c h a n n e l$, calcium channel. ${ }^{a}$ indicates significantly different from No Chest Pain; No Ischemia $(p<.05) ;{ }^{b}$ indicates significantly different from Silent Ischemia $(p<.05) ;{ }^{c}$ indicates significantly different from Chest Pain, No Ischemia Group $(p<.05) ;{ }^{d}$ indicates significantly different from Ischemia with Chest Pain $(p<.05)$ 
Table 2: Exercise stress test characteristics as related to ischemia and chest pain

\begin{tabular}{|c|c|c|c|c|c|c|c|}
\hline $\begin{array}{l}\text { Stress test results } \\
\qquad M \pm S D\end{array}$ & $\begin{array}{l}\text { No Chest Pain; } \\
\text { No Ischemia } \\
\quad(n=145)\end{array}$ & $\begin{array}{c}\text { Silent Ischemia } \\
(n=55)\end{array}$ & $\begin{array}{c}\text { Chest Pain; No } \\
\text { Ischemia } \\
(n=23)\end{array}$ & $\begin{array}{c}\text { Ischemia with } \\
\text { Chest Pain } \\
(n=23)\end{array}$ & $\begin{array}{c}\mathbf{N} \text { missing } \\
\text { data }\end{array}$ & $F / x^{2}$ & $\mathbf{P}$ \\
\hline Duration (s) & $458 \pm 108$ & $471 \pm 93$ & $456 \pm 90$ & $432 \pm 90$ & 1 & .81 & .49 \\
\hline $\begin{array}{l}\text { METS } \\
\left(3.5 \mathrm{ml} / \mathrm{kg} / \mathrm{O}_{2} / \mathrm{min}\right)\end{array}$ & $8.24 \pm 1.8$ & $8.25 \pm 1.7$ & $8.11 \pm 1.7$ & $7.46 \pm 1.8$ & 0 & 1.42 & .24 \\
\hline$\% \mathrm{MPHR}$ & $90.74 \pm 12.9$ & $87.47 \pm 13.3$ & $86.22 \pm 12.7$ & $80.30 \pm 15.4^{a, b}$ & 0 & 4.65 & .004 \\
\hline Baseline SBP $(\mathrm{mmHg})$ & $130.65 \pm 16.6$ & $133.64 \pm 17.2$ & $131.85 \pm 17.2$ & $130.46 \pm 17.3$ & 2 & .44 & .72 \\
\hline Baseline DBP $(\mathrm{mmHg})$ & $81.89 \pm 10.9$ & $81.07 \pm 8.4$ & $81.74 \pm 8.1$ & $83.04 \pm 12.9$ & 2 & .20 & .89 \\
\hline Baseline HR (bpm) & $73.62 \pm 14.8$ & $71.20 \pm 14.9$ & $68.13 \pm 9.1$ & $69.46 \pm 13.8$ & 2 & 1.45 & .23 \\
\hline Peak SBP $(\mathrm{mmHg})$ & $164.66 \pm 27.7$ & $163.74 \pm 23$ & $163.13 \pm 24.5$ & $159.73 \pm 24.7$ & 3 & 26 & .86 \\
\hline Peak DBP $(\mathrm{mmHg})$ & $83.22 \pm 11.2$ & $83.29 \pm 8.9$ & $83.74 \pm 9.7$ & $84.39 \pm 13.8$ & 3 & .08 & .97 \\
\hline Peak HR (bpm) & $137.53 \pm 24.7$ & $129.63 \pm 21.1^{a}$ & $129.48 \pm 26.3$ & $125.57 \pm 28.2^{a}$ & 3 & 2.75 & .044 \\
\hline $\begin{array}{l}\text { Self-reported Chest } \\
\text { Pain score }(0-10)\end{array}$ & $0.10 \pm 0.61$ & 0 & $4.30 \pm 2.93^{a}$ & $4.09 \pm 2.92^{a}$ & 0 & 119.27 & $<.001$ \\
\hline
\end{tabular}

Note: METs, Metabolic Equivalent; MPHR, Maximum Predicted Heart Rate; SBP, Systolic blood pressure; DBP, Diastolic blood pressure, HR, Heart rate. ${ }^{a}$ indicates significantly different from No Chest Pain; No Ischemia $(p<.05) ;{ }^{b}$ indicates significantly different from Silent Ischemia $(p<.05)$ 
Table 3: Logistic regressions to examine the association between the presence of pain across the whole sample, and examine a 3-way interaction between PA, NA and Ischemia

\begin{tabular}{|c|c|c|c|c|c|c|c|c|c|c|c|c|}
\hline & \multicolumn{3}{|c|}{ Model 1} & \multicolumn{3}{|c|}{ Model $2 \dagger$} & \multicolumn{3}{|c|}{ Model 3} & \multicolumn{3}{|c|}{ Model $4 \dagger$} \\
\hline & $\beta$ & $95 \% \mathrm{Cls}$ & $p$ & $\beta$ & $95 \% \mathrm{Cls}$ & $p$ & $\beta$ & $95 \% \mathrm{Cls}$ & $p$ & $\beta$ & $95 \% \mathrm{Cls}$ & $p$ \\
\hline PA & 0.007 & $0.00-0.01$ & .048 & 0.01 & $0.00-0.02$ & .038 & -0.02 & $-0.05-0.00$ & .06 & -0.03 & $-0.05--0.00$ & .02 \\
\hline NA & 0.02 & $0.01-0.02$ & $<.001$ & 0.02 & $0.01-0.02$ & $<.001$ & -0.03 & $-0.07-0.00$ & .06 & -0.04 & $-0.07--0.01$ & .02 \\
\hline Ischemia & 0.16 & $0.06-0.27$ & .002 & 0.16 & $0.04-0.27$ & .007 & -1.10 & $-2.36-0.17$ & .09 & -1.17 & $-2.43-0.09$ & .07 \\
\hline$P A^{*} N A$ & - & - & - & - & - & - & -0.00 & $-0.00-0.00$ & .09 & -0.00 & $-0.00-0.00$ & .07 \\
\hline $\begin{array}{l}\text { PA* }^{*} \\
\text { Ischemia }\end{array}$ & - & - & - & - & - & - & 0.04 & $-0.01-0.08$ & .10 & 0.04 & $-0.00-0.08$ & .08 \\
\hline $\begin{array}{l}\mathrm{NA}^{*} \\
\text { Ischemia }\end{array}$ & - & - & - & - & - & - & 0.07 & $0.01-0.13$ & .03 & 0.07 & $0.01-0.13$ & .02 \\
\hline $\begin{array}{l}P^{*} \mathrm{NA}^{*} \\
\text { Ischemia }\end{array}$ & - & - & - & - & - & - & -0.00 & $-0.00-0.00$ & .09 & -0.00 & $-0.00-0.00$ & .07 \\
\hline
\end{tabular}

$\beta$ - Beta-estimate; 95\% Cl-95\% Confidence Intervals; † adjusted for age, sex, total exercise METS, prescription of anti-ischemic medications, and analgesic medication use 
Table 4: Logistic regressions to examine the association between the presence of pain in ischemic and non-ischemic patients

Non-ischemic patients only

\begin{tabular}{|c|c|c|c|c|c|c|c|c|c|c|c|c|c|c|}
\hline & \multicolumn{4}{|c|}{ Model 1} & \multicolumn{4}{|c|}{ Model $2 †$} & \multicolumn{3}{|c|}{ Model $3 †$} & \multicolumn{3}{|c|}{ Model 4 † } \\
\hline & $\beta$ & OR & $\begin{array}{c}\text { OR } \\
95 \% \\
\mathrm{Cl}\end{array}$ & $p$ & $\beta$ & OR & $\begin{array}{c}\text { OR } \\
95 \% \\
\mathrm{Cl}\end{array}$ & $p$ & $\beta$ & $\begin{array}{c}\beta \\
\begin{array}{c}\text { 9 } \\
\mathrm{Cl}\end{array}\end{array}$ & $p$ & $\beta$ & $\begin{array}{c}\beta \\
95 \% \\
\mathrm{Cl}\end{array}$ & $p$ \\
\hline PA & 0.06 & 1.07 & $\begin{array}{r}0.99- \\
1.14\end{array}$ & 0.075 & 0.07 & 1.07 & $\begin{array}{r}1.00- \\
1.15\end{array}$ & 0.070 & -0.21 & $\begin{array}{r}-0.46- \\
0.04\end{array}$ & 0.096 & -0.23 & $\begin{array}{c}-0.51- \\
0.02\end{array}$ & 0.081 \\
\hline NA & 0.09 & 1.10 & $\begin{array}{r}1.02- \\
1.18\end{array}$ & 0.010 & 0.10 & 1.11 & $\begin{array}{r}1.03- \\
1.20\end{array}$ & 0.007 & -0.32 & $\begin{array}{c}-0.71- \\
0.07\end{array}$ & 0.110 & -0.35 & $\begin{array}{c}-0.79- \\
0.04\end{array}$ & 0.098 \\
\hline$P A^{*} N A$ & - & - & - & - & - & - & - & - & 0.01 & $\begin{array}{c}0- \\
0.03\end{array}$ & 0.036 & 0.02 & $\begin{array}{c}0- \\
0.03\end{array}$ & 0.031 \\
\hline
\end{tabular}

Ischemic patients only

\begin{tabular}{|c|c|c|c|c|c|c|c|c|c|c|c|c|c|c|}
\hline & \multicolumn{4}{|c|}{ Model 1} & \multicolumn{4}{|c|}{ Model $2 \dagger$} & \multicolumn{3}{|c|}{ Model $3 †$} & \multicolumn{3}{|c|}{ Model $4 †$} \\
\hline & $B$ & OR & $\begin{array}{c}\text { OR } \\
95 \% \\
\mathrm{Cl}\end{array}$ & $P$ & $B$ & OR & $\begin{array}{c}\text { OR } \\
95 \% \\
\mathrm{Cl}\end{array}$ & $p$ & $B$ & $\begin{array}{c}\beta \quad 95 \% \\
\mathrm{Cl}\end{array}$ & $p$ & $B$ & $\begin{array}{c}\beta \\
95 \% \\
C l\end{array}$ & $p$ \\
\hline PA & 0.04 & 1.04 & $\begin{array}{c}0.96- \\
1.14\end{array}$ & 0.31 & 0.06 & 1.07 & $\begin{array}{c}0.96- \\
1.18\end{array}$ & 0.22 & 0.09 & $\begin{array}{c}-0.16- \\
0.34\end{array}$ & 0.48 & 0.04 & $\begin{array}{c}-0.26- \\
0.29\end{array}$ & 0.79 \\
\hline NA & 0.13 & 1.14 & $\begin{array}{c}1.03- \\
1.25\end{array}$ & 0.008 & 0.13 & 1.13 & $\begin{array}{c}1.02- \\
1.27\end{array}$ & 0.026 & 0.19 & $\begin{array}{c}-0.14- \\
0.52\end{array}$ & 0.26 & 0.09 & $\begin{array}{c}-0.32- \\
0.43\end{array}$ & 0.63 \\
\hline $\mathrm{PA}^{*} \mathrm{NA}$ & - & - & - & - & - & - & - & - & -0.00 & $\begin{array}{c}-0.01- \\
0.01\end{array}$ & 0.69 & 0.00 & $\begin{array}{c}-0.01- \\
0.02\end{array}$ & 0.84 \\
\hline
\end{tabular}


Note: $\beta$ - Beta-estimate; $95 \% \mathrm{Cl}-95 \%$ Confidence Intervals; $†$ adjusted for age, sex, total exercise METS, prescription of anti-ischemic medications, and analgesic medication use. Sample sizes: Ischemic patients only ( $N=78)$; Non-ischemic patients only $(\mathrm{N}=172)$ 


\section{Figure 1: Recruitment of participants}

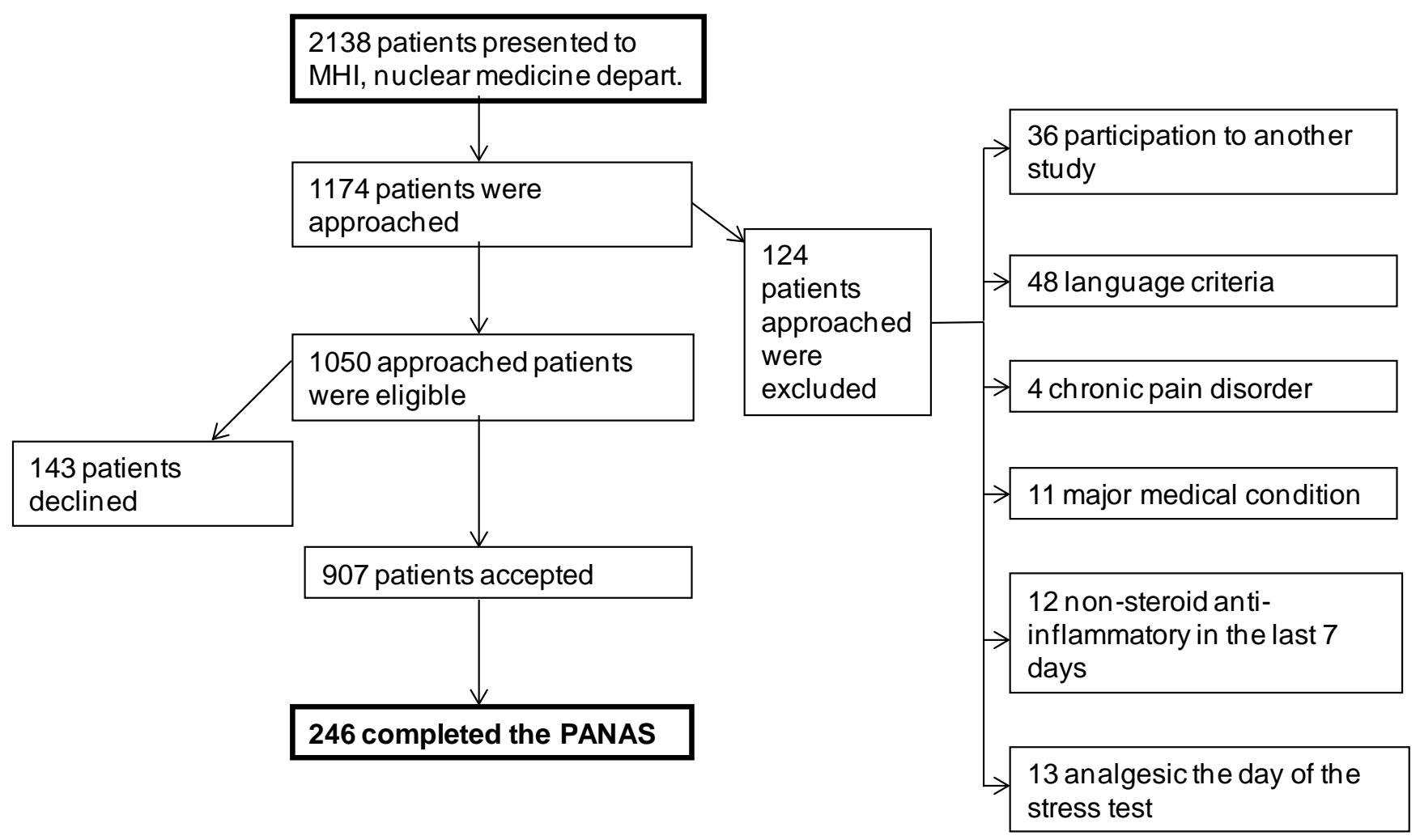


Figure 2: Chest pain reporting by positive affect in patients without ischemia (left) and patients with ischemia (right). Dashed line indicates Low NA, Solid line indicates High NA.
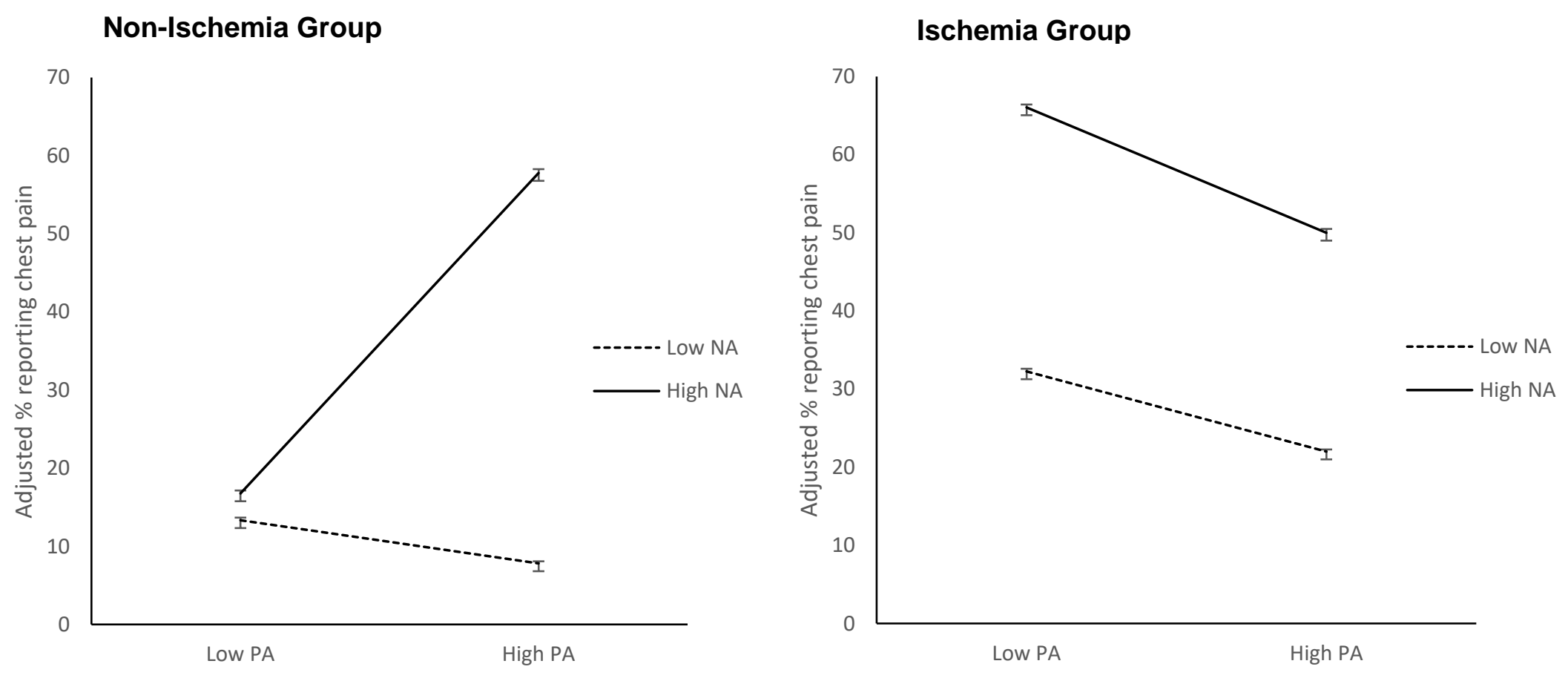

Note: High PA: PANAS positive affect score > 33.9; Low PA: PANAS positive affect score < 26.1; High NA: PANAS negative affect score > 19.9; Low NA: PANAS negative affect score $<13.1$. 


\section{References}

1. WHO WHO. The top 10 causes of death. World Health Organization; 2012 [cited 201406 juin 2014]; Available from:

http://www.who.int/mediacentre/factsheets/fs310/en/index2.html.

2. Mozaffarian D, Benjamin EJ, Go AS, Arnett DK, Blaha MJ, Cushman M, Das SR, de Ferranti S, Després J-P, Fullerton HJ, Howard VJ, Huffman MD, Isasi CR, Jiménez MC, Judd SE, Kissela BM, Lichtman JH, Lisabeth LD, Liu S, Mackey RH, Magid DJ, McGuire DK, Mohler ER, Moy CS, Muntner P, Mussolino ME, Nasir K, Neumar RW, Nichol G, Palaniappan L, Pandey DK, Reeves MJ, Rodriguez CJ, Rosamond W, Sorlie PD, Stein J, Towfighi A, Turan TN, Virani SS, Woo D, Yeh RW, Turner MB. Heart Disease and Stroke Statistics-2016 Update: A Report From the American Heart Association. Circulation. 2015.

3. Cecil RL, Goldman L, Bennett JC. Cecil textbook of medicine. Philadelphia, PA ; St. Louis, MO: W.B. Saunders ; MD Consult LLC; 2004 [updated 200020 octobre 2013]; Available from: http://home.mdconsult.com/das/book/view/882

4. Gutterman DD. Silent myocardial ischemia. Circ J. 2009;73:785-97.

5. Jain D, Burg M, Soufer R, Zaret BL. Prognostic implications of mental stressinduced silent left ventricular dysfunction in patients with stable angina pectoris. Am J Cardiol. 1995;76:31-5.

6. Krantz DS, Santiago HT, Kop WJ, Bairey Merz CN, Rozanski A, Gottdiener JS. Prognostic value of mental stress testing in coronary artery disease. Am J Cardiol. 1999;84:1292-7.

7. Babyak MA, Blumenthal JA, Hinderliter A, Hoffman B, Waugh RA, Coleman RE, Sherwood A. Prognosis after change in left ventricular ejection fraction during mental stress testing in patients with stable coronary artery disease. Am J Cardiol. 2010;105:25-8.

8. Cohn PF, Fox KM, Daly C. Silent myocardial ischemia. Circulation. 2003;108:1263-77.

9. Mulcahy DA. The return of silent ischaemia? Not really. Heart. 2005;91:1249-50. 10. Deedwania PC, Carbajal EV. Silent myocardial ischemia. A clinical perspective. Arch Intern Med. 1991;151:2373-82.

11. Mant J, McManus RJ, Oakes RA, Delaney BC, Barton PM, Deeks JJ, Hammersley L, Davies RC, Davies MK, Hobbs FD. Systematic review and modelling of the investigation of acute and chronic chest pain presenting in primary care. Health Technol Assess. 2004;8:iii, 1-158.

12. Roest AM, Martens EJ, de Jonge P, Denollet J. Anxiety and risk of incident coronary heart disease: a meta-analysis. J Am Coll Cardiol. 2010;56:38-46.

13. Lichtman JH, Froelicher ES, Blumenthal JA, Carney RM, Doering LV, FrasureSmith N, Freedland KE, Jaffe AS, Leifheit-Limson EC, Sheps DS, Vaccarino V, Wulsin $\mathrm{L}$. Depression as a risk factor for poor prognosis among patients with acute coronary syndrome: systematic review and recommendations: a scientific statement from the American Heart Association. Circulation. 2014;129:1350-69. 
14. Lavoie KL, Fleet RP, Lesperance F, Arsenault A, Laurin C, Frasure-Smith N, Bacon SL. Are exercise stress tests appropriate for assessing myocardial ischemia in patients with major depressive disorder? Am Heart J. 2004;148:621-7.

15. Paine NJ, Bacon SL, Pelletier R, Arsenault A, Diodati JG, Lavoie KL. Do Women With Anxiety or Depression Have Higher Rates of Myocardial Ischemia During Exercise Testing Than Men? Circ Cardiovasc Qual Outcomes. 2016;9:S53-S61.

16. Sheps DS, Creed F, Clouse RE. Chest pain in patients with cardiac and noncardiac disease. Psychosom Med. 2004;66:861-7.

17. Raselli C, Broderick JE. The association of depression and neuroticism with pain reports: a comparison of momentary and recalled pain assessment. J Psychosom Res. [Research Support, N.I.H., Extramural]. 2007;62:313-20.

18. Tiengo M. Pain perception, brain and consciousness. Neurol Sci. 2003;24 Suppl 2:S76-9.

19. Strand EB, Zautra AJ, Thoresen M, Odegard S, Uhlig T, Finset A. Positive affect as a factor of resilience in the pain-negative affect relationship in patients with rheumatoid arthritis. J Psychosom Res. 2006;60:477-84.

20. Jones A, Spindler H, Jorgensen MM, Zachariae R. The effect of situation-evoked anxiety and gender on pain report using the cold pressor test. Scand J Psychol. 2002;43:307-13.

21. Conant LL. Psychological Variables Associated with Pain Perceptions Among Individuals with Chronic Spinal Cord Injury Pain. J Clin Psychol Med Settings. 1998;5:71-90.

22. Sela RA, Bruera E, Conner-spady B, Cumming C, Walker C. Sensory and affective dimensions of advanced cancer pain. Psychooncology. 2002;11:23-34.

23. Damen NL, Pelle AJ, Boersma E, Serruys PW, van Domburg RT, Pedersen SS. Reduced positive affect (anhedonia) is independently associated with 7-year mortality in patients treated with percutaneous coronary intervention: results from the RESEARCH registry. European journal of preventive cardiology. [Research Support, Non-U.S. Gov't]. 2013;20:127-34.

24. Bekkouche NS, Wawrzyniak AJ, Whittaker KS, Ketterer MW, Krantz DS.

Psychological and physiological predictors of angina during exercise-induced ischemia in patients with coronary artery disease. Psychosom Med. 2013;75:413-21.

25. L'enfant C. Chest pain of cardiac and noncardiac origin. Metabolism. 2010;59:S41-S6.

26. Huffman JC, Pollack MH, Stern TA. Panic Disorder and Chest Pain: Mechanisms, Morbidity, and Management. Prim Care Companion J Clin Psychiatry. 2002;4:54-62.

27. Davies RF, Linden W, Habibi H, Klinke WP, Nadeau C, Phaneuf DC, Lepage S, Dessain P, Buttars JA. Relative importance of psychologic traits and severity of ischemia in causing angina during treadmill exercise. Canadian Amlodipine/Atenolol in Silent Ischemia Study (CASIS) Investigators. J Am Coll Cardiol. 1993;21:331-6.

28. Lautenbacher S, Spernal J, Schreiber W, Krieg JC. Relationship between clinical pain complaints and pain sensitivity in patients with depression and panic disorder. Psychosom Med. 1999;61:822-7. 
29. Gil KM, Carson JW, Porter LS, Scipio C, Bediako SM, Orringer E. Daily mood and stress predict pain, health care use, and work activity in African American adults with sickle-cell disease. Health Psychol. 2004;23:267-74.

30. Gil KM, Carson JW, Porter LS, Ready J, Valrie C, Redding-Lallinger R,

Daeschner C. Daily stress and mood and their association with pain, health-care use, and school activity in adolescents with sickle cell disease. J Pediatr Psychol. 2003;28:363-73.

31. Zautra AJ, Johnson LM, Davis MC. Positive Affect as a Source of Resilience for Women in Chronic Pain. J Consult Clin Psychol. 2005;73:212-20.

32. Pressman SD, Cohen S. Does Positive Affect Influence Health? Psychol Bull. 2005;131:925-71.

33. Ostir GV, Markides KS, Peek MK, Goodwin JS. The association between emotional well-being and the incidence of stroke in older adults. Psychosom Med. $2001 ; 63: 210-5$.

34. van Domburg RT, Scmidt Pedersen S, van den Brand MJ, Erdman RA. Feelings of being disabled as a predictor of mortality in men 10 years after percutaneous coronary transluminal angioplasty. J Psychosom Res. 2001;51:469-77.

35. Davis MC, Zautra AJ, Smith BW. Chronic pain, stress, and the dynamics of affective differentiation. J Pers. 2004;72:1133-59.

36. American Society of Nuclear Cardiology. Updated imaging guidelines for nuclear cardiology procedures, part 1. J Nucl Cardiol. 2001;8:G5-G58.

37. Anagnostopoulos C, Harbinson M, Kelion A, Kundley K, Loong CY, Notghi A, Reyes E, Tindale W, Underwood SR. Procedure guidelines for radionuclide myocardial perfusion imaging. Heart (British Cardiac Society). 2004;90 Suppl 1:i1-10.

38. Watson D, Clark LA. The PANAS-X: Manual for the Positive and Negative Affect Schedule-Expanded Form. 1994.

39. Russell JA, Carroll JM. On the bipolarity of positive and negative affect. Psychol Bull. 1999;125:3-30.

40. McNair DM, Lorr M, Droppleman LF. Manual: Profile of Mood States. Educational and Industrial Testing Services. 1971.

41. Denollet J, De Vries J. Positive and negative affect within the realm of depression, stress and fatigue: the two-factor distress model of the Global Mood Scale (GMS). J Affect Disord. 2006;91:171-80.

42. Borg G. Borg's perceived exertion and pain scales. Champaign, IL, US: Human Kinetics; 1998.

43. Gibbons RJ, Balady GJ, Timothy Bricker J, Chaitman BR, Fletcher GF, Froelicher VF, Mark DB, McCallister BD, Mooss AN, O'Reilly MG, Winters JWL, Gibbons RJ, Antman EM, Alpert JS, Faxon DP, Fuster V, Gregoratos G, Hiratzka LF, Jacobs AK, Russell RO, Smith JSC. ACC/AHA 2002 guideline update for exercise testing: summary article: A report of the American college of cardiology/American heart association task force on practice guidelines (committee to update the 1997 exercise testing guidelines). J Am Coll Cardiol. 2002;40:1531-40.

44. Libby P, Bonow RO, Mann DL, Zipes DP. Libby: Braunwald's Heart Disease: A Textbook of Cardiovascular Medicine. 8th ed: Saunders; 2007. 
45. Bacon SL, Lavoie KL, Campbell TS, Fleet R, Arsenault A, Ditto B. The role of ischaemia and pain in the blood pressure response to exercise stress testing in patients with coronary heart disease. J Hum Hypertens. 2006;20:672-8.

46. Rubin DB. Multiple Imputation for Nonresponse in Surveys. New York: Wiley; 1987.

47. Barzi F, Woodward M. Imputations of Missing Values in Pratice: Results from Imputations of Serum Cholesterol in 28 Cohort Studies. Am J Epidemiol. 2004;160:3445.

48. Harrell FE. Regression Modeling Strategies: With Applications to Linear Models, Logistic Regression, and Survival Analysis. Springer Science \& Business Media, editor. New York: Springer; 2001.

49. Fleet RP, Dupuis G, Marchand A, Burelle D, Arsenault A, Beitman BD. Panic disorder in emergency department chest pain patients: prevalence, comorbidity, suicidal ideation, and physician recognition. Am J Med. 1996;101:371-80.

50. Foldes-Busque G, Marchand A, Chauny J-M, Poitras J, Diodati J, Denis I, Lessard M-J, Pelland M-Ë, Fleet R. Unexplained chest pain in the ED: could it be panic? The American Journal of Emergency Medicine. 2011;29:743-51.

51. Khan RS, Ahmed K, Blakeway E, Skapinakis P, Nihoyannopoulos L, Macleod K, Sevdalis N, Ashrafian H, Platt M, Darzi A, Athanasiou T. Catastrophizing: a predictive factor for postoperative pain. Am J Surg. [Research Support, Non-U.S. Gov't Review]. 2011;201:122-31.

52. Goubert L, Crombez G, Van Damme S. The role of neuroticism, pain catastrophizing and pain-related fear in vigilance to pain: a structural equations approach. Pain. [Comparative Study]. 2004;107:234-41.

53. Costa PT, Jr. Influence of the normal personality dimension of neuroticism on chest pain symptoms and coronary artery disease. The American Journal of Cardiology. [Review]. 1987;60:20J-6J.

54. Bruehl S, Chung OY, Burns JW. Anger expression and pain: an overview of findings and possible mechanisms. J Behav Med. 2006;29:593-606.

55. Hadjistavropoulos HD, Craig KD. Acute and chronic low back pain: cognitive, affective, and behavioral dimensions. J Consult Clin Psychol. [Research Support, NonU.S. Gov't]. 1994;62:341-9.

56. Pelle AJ, Pedersen SS, Szabo BM, Denollet J. Beyond Type D personality: reduced positive affect (anhedonia) predicts impaired health status in chronic heart failure. Quality of life research : an international journal of quality of life aspects of treatment, care and rehabilitation. [Research Support, Non-U.S. Gov't]. 2009;18:689-98. 57. Masters KS, Wallston KA. Canonical Correlation Reveals Important Relations between Health Locus of Control, Coping, Affect and Values. J Health Psychol. 2005;10:719-31.

58. Fillingim RB. Individual differences in pain responses. Current rheumatology reports. [Research Support, N.I.H., Extramural Review]. 2005;7:342-7.

59. Kimble LP, McGuire DB, Dunbar SB, Fazio S, De A, Weintraub WS, Strickland OS. Gender differences in pain characteristics of chronic stable angina and perceived 
physical limitation in patients with coronary artery disease. Pain. [Comparative Study]. 2003;101:45-53.

60. Foldes-Busque G, Fleet R, Poitras J, Chauny J-M, Belleville G, Denis I, Diodati JG, Pelland M-Ë, Lessard M-J, Marchand A. Preliminary Investigation of the Panic Screening Score for Emergency Department Patients With Unexplained Chest Pain. Acad Emerg Med. 2011;18:322-5.

61. Ketterer MW, Smith TW. Self-reported versus other-reported distress and coronary artery calcification. Psychosom Med. 2011;73:721; author reply -2. 
